\title{
Parameters of the Quality and Efficiency of the Educational System from the Aspect of Ergonomics
}

\section{Martin Lorko*}

\begin{abstract}
In the article, the selected ergonomic parameters improving basic educational systems (educational workplaces) are analysed from the point of view of a teacher and a student. The emphasis is put on the complex ergonomic optimization of these educational systems so as to improve their quality and efficiency by increasing productivity and quality of work in the systems.
\end{abstract}

Key words: ergonomics, educational system, productivity, quality, efficiency.

\section{Introduction}

The current educational systems in Slovakia do not correspond to the trends in industrially advanced countries. The consequence of this is a declining level of applicable knowledge and skills of the graduates in practice. Improvement of this situation requires a complex solution of the educational systems, which should provide highly qualified and creative professionals for practice, able to solve current and future expected tasks arising from the requirement to improve the quality of life of the human population. Requirements for educational processes and conditions, under which the educational processes are currently realized, need to be changed, as they lead to low efficiency of education. The educational system must be humane, productive, first quality, creative and motivating in terms of the development of personality characteristics of a student as well as a teacher. Therefore, it is necessary to pay the utmost attention to the ergonomic optimization of basic educational systems in educational institutions.

\section{Ergonomic parameters of basic educational systems}

Practice confirms that the complex ergonomic optimization of the work system and working conditions in educational institutions can increase productivity and work quality of teachers, students and service personnel, which in turn leads to improved quality and efficiency of education in these institutions.

\footnotetext{
* Martin Lorko, Dubnica Technological Institute, Dubnica nad Váhom, Slovakia; martin.lorko@gmail.com
} 


\section{Acta Technologica Dubnicae \\ volume 1, 2011, issue 2}

Ergonomic parameters increasing the quality and efficiency of education in educational institutions should be sought primarily in educational centres. These parameters are hidden in the working conditions of teachers, students and service personnel, the ergonomic requirements for work equipment, methods of work, organization of education, work environment, communication, setting up the aims of education and achieving them, the optimization of energy, material, information, and also financial flows.

Because of the number of elements and processes that affect the quality and efficiency of education, it is necessary to solve this problem systematically. Education is perceived as the system of education, in which the quality of the individual subsystems (or components) and processes that take place between them, affects the quality and efficiency of the entire educational system. The author's presented model of educational system treats the surrounding environment, and its subsystems have ties to the environment of educational system or other educational centres.

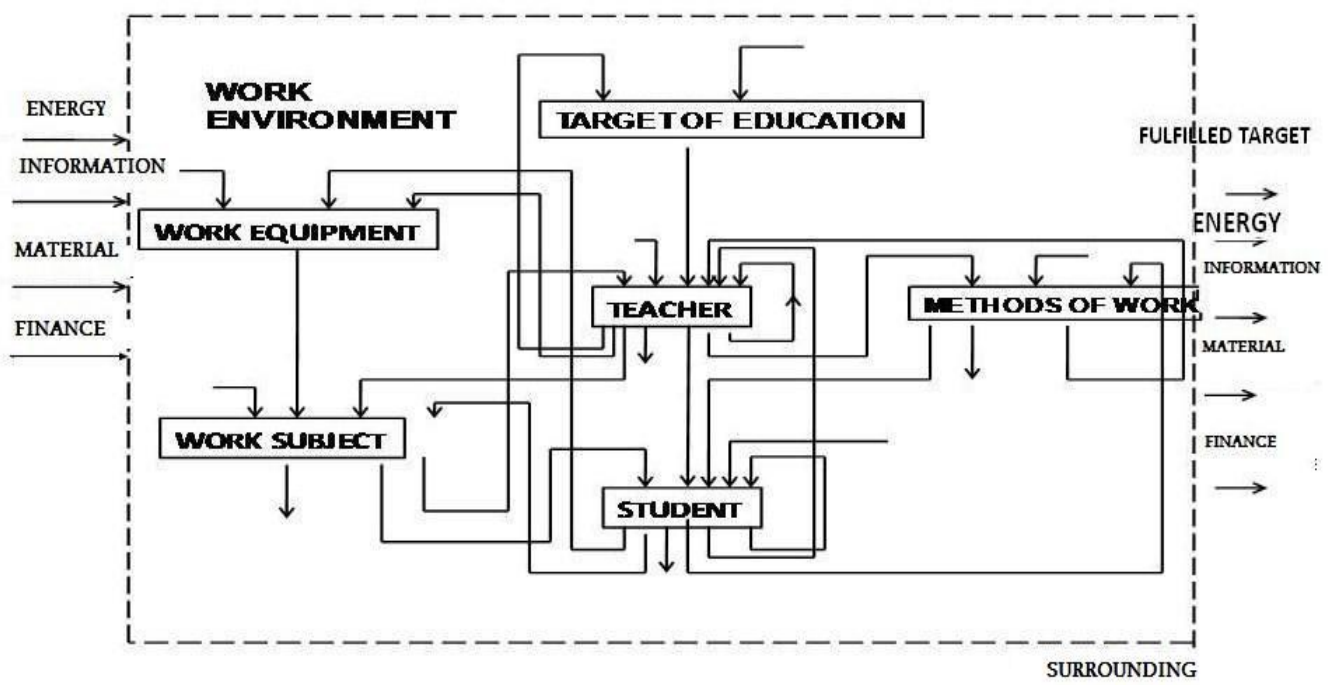

Figure1 A simplified model of the basic educational system in educational institutions

Basic subsystems of education are teacher/s and student/s. There are also targets of education, work methods, work equipment, work items and work environment to be concerned. In terms of examination, these subsystems may consist of other subsystems or elements. Teachers, in interaction with students, use their own experiences, various work methods and diverse work equipment in performing their jobs. Students also work with already acquired knowledge and experiences, they recognize new learning 
and working techniques, work equipment and work items, which they use for further effective acquisition of knowledge, experience and skills. The target of this education is a well prepared graduate demanded by the labour market.

\subsection{Requirements for teachers}

The current requirements for teachers are often enormous (to register, to receive, to process, to reproduce excess amount of rapidly changing information, to carry out the work within binding deadlines, often in poor working conditions and in a low-paid job). Therefore, we should not forget the quality of life of teachers and their motivation, regarding their important social role and tasks, which should be effectively implemented. Only a quality teacher has the potential to educate quality graduates and only a personality can bring up personality. Therefore, it is necessary to pay the utmost attention to the choice of top quality teachers, their training and motivation, as well as the working conditions. Unfortunately, the role of a teacher does not correspond with the social requirements putting emphasis on the entire educational system in the current social conditions in Slovakia. We lack a coherent system of continuous educational and specialized professional training. The teacher must have the ability to learn constantly (to "starve" for the latest knowledge of science and technology). Knowledge, understanding and skills of teachers in the given subject and their effective use in educational process are fundamental conditions of first quality of their work.

Systematic professional development is considered to be a professional responsibility for teachers in more than 20 European countries and regions. It is voluntary in Slovakia, but clearly linked to the career benefits and salary increases. It is necessary to determine the appropriate minimum of a year time limit for these activities of teachers for the given subjects (EURYDICE, 2008).

A very important requirement for the teacher is to think positively, to be humane to students and colleagues, to be able to motivate, to be empathetic, friendly, to be able to explain and develop the creativity of students in science and research. The teacher should receive students' feedback during the teaching process to be able to lead them properly to the development of their critical thinking and solution of various problems. If teachers do not understand their position, position of their students and their current situation, they will never reach their educational target.

\subsection{Requirements for students}

The basic requirement for a student is a positive recommendation and certificate of previous educational institutions, in which the student obtained the required knowledge 


\section{Acta Technologica Dubnicae}

volume 1, 2011, issue 2

and skills, as well as the recommendation to continue in other forms of study. Educational institutions in order to maintain the high quality of their graduates should pay close attention to the selection of the candidates for study. In addition to the verification of their knowledge, experience and skills, it is necessary to pay attention to their internal motivation for the study in the given course and the depth of their interest in the given area of education. We must not neglect the other physical, mental and sensory conditions of the candidate for appropriate kind of education. The system of education must be set so that the students should take the interdependence on other people (understand the meaning of humanism and pluralism), in order to be able to learn throughout their lives to know how to use the acquired knowledge and skills effectively in practice and to be able to solve their own problems (to make their own decision and assume full responsibility for it). The most important thing for the students' life in a global society is to understand local and global problems of humanity and lead them to seek ways of their solution (Doyle, 2008).

\subsection{Requirements for work equipment}

Under the work equipment we understand all material tools (working tools, accessories, furniture, textbooks, computers, etc.), which are used as the equipment of a workplace to ensure effective educational process and facilitate all-round development of personality characteristics of teachers and students. The basic ergonomic requirements for the work equipment should include mainly the optimal technical facilities for the particular area of education, their humanity, comfort, high functionality and aesthetic level. Educational institutions should use the latest teaching aids to meet the essential criteria described in ergonomic standards. Educational centres should be equipped with ICT to ensure optimal audio-visual communication between teachers and students. We must not forget the risks arising from these technologies (the loading of electromagnetic smog, fast fatigue, deterioration of eyes and other body functions) that affect students and teachers.

\subsection{Requirements for educational methods}

Educational methods include lectures, group discussions, individual presentations, homework, seminars, workshops, conferences, brainstorming, role playing, case studies, subject-oriented learning, experiential learning, project-oriented learning, independent study, consultation, e-learning, etc. Most of students evaluate lectures as the best teaching method. However, a group discussion is often evaluated as more effective because students do not rely solely on mechanical learning and discussion encourages greater creativity. Therefore, when a teaching method is chosen by a teacher, it is necessary to consider not only the experience of a teacher, but also the 
perception of students and their previous efficiency assessment of teaching methods, as well as their suggestions for improvement.

So called experiential learning is an important area in the educational process, which is based on personal activity. "Tell me and I will forget. Show me and maybe I will not forget. Involve me and I will understand" (Chinese proverb). If we include more senses and invest more energy, the experience will be more intense and will have greater effect. The financial aspects of educational process can significantly affect the choice of educational method.

\subsection{Organisation of education}

A general organization of education, i.e. time (schedule of educational activities), spatial (where and under what conditions) and staffing (who will be implemented) does not play less important role in optimizing the educational system. There is a scope of flexible educational programs, efficient location, organization and equipment of educational area for individual or group education, seminars, lectures, practical exercises, laboratory tests, and so on.

\subsection{Requirements for work environment}

The work environment in educational institutions must meet the basic ergonomic parameters of lighting comfort and visual communication (illumination, colour and spatial solution of workplaces in accordance with the action, which will take place there, elimination of excessive electromagnetic radiation), acoustic comfort and audio communication (exclusion of noise, vibration and shock), climate comfort (optimum parameters of temperature, humidity and airflow, elimination of unpleasant radiant heat and sudden changes in air pressure), dust-free environment, exclusion of toxic chemicals of various state, protection against hazardous biological factors, as well as providing a favourable psychosocial climate.

\subsection{Requirements for the target of education}

The target of education must be clear, transparent, and understandable and accepted by students and teachers. The main target may include a set of partial targets, the achievement of which will move us to the main target. The target of education is also the output of the basic system of education, thus we should pay significant attention to it. Too big and too ambitious targets may not be fulfilled, which will threaten the quality and efficiency of education. Too small targets may lead to uninterested students. Therefore, the main target should be based primarily on the requirements 
arising from the needs of practice, which are included in the profile of the graduate of the given study. From the main target are derived the basic targets and from these, the partial targets, which are achieved within the educational activities. The target must meet the form and content requirements and must conform to the schedule of study, so that the student can master the study material by logical sequence and know how to use it practically or demonstrate the knowledge in examination.

\subsection{Requirements for communication during the educational process}

Mutual high-quality communication between teachers and students means that they know the object of communication and the communication code and the exchange of information is open and truthful. Information sources, from which they arise, are genuine and credible, informational noises are excluded. Communication impact on a student develops in the way, where as many as possible sensory organs are involved into the learning process and educational activity leaves a deep impression (experience) in a student so he/she will be proud to say that after this experience is smarter and more capable in the field.

\subsection{Requirements for the control of achieved target of education}

The control of the achieved educational target (in the form of tests, examinations, etc.) cannot be a threat. It must be a natural way of verifying the knowledge and skills in application of the acquired knowledge in solving practical problems with the possibility to re-add the missing knowledge. This creates a possibility of solution of individual projects, examination of knowledge, practical verification of skills, etc.

The various methods including self-evolution, teaching portfolio analysis, evaluation of students' knowledge and teaching methods evaluated by the students can be used for the evaluation of the efficiency of the system of education. Students must be assured that the evaluations given by teachers and educational institutions are objective and true. Otherwise, it is unlikely that the public will take a given educational institution seriously.

The most acceptable criterion for measuring a good education is the amount of voluntary participation of students in the classroom. Many scientists in the field of education argue that students are legitimate judges of the efficiency of education and are qualified to express their satisfaction or dissatisfaction with education (Hoyt Pallett, 1999). 


\section{Acta Technologica Dubnicae}

volume 1, 2011, issue 2

\section{Conclusions}

The overall quality and efficiency of education depends on the quality of the educational process and under what conditions it is carried out. The best indicator of the efficiency of the education is the success of graduates in job-hunting and their professional competence use as a short-to-medium term effect of the received education. Efficiency and quality are interrelated and conditional. Products of education, which appear to be effective, are used as inputs into a new process to its improvement. Efficiency is thus a tool for improving the educational system and its expected results.

Educational institutions should be a motor of economy, a place of creation and preservation of knowledge. They should prepare students for research and teaching, as well as prepare professionals for market needs and international cooperation in a given discipline as well as continually provide lifelong education of professionals. We must not forget that one of the main targets of education should be: to teach students to be able to take control of their own development, to take their destiny into their own hands and to contribute to human progress and higher quality of their own lives by their education (Franc - Zounková, 2007). It will not be possible to achieve the target without efficient educational system, whose efficiency is linked to productivity and quality of work at individual educational workplaces. That will depend on the consistent application of ergonomic parameters in the basic educational systems.

\section{References}

DOYLE, T.: Evaluating Teachers Effectiveness. Retrieved July 24, 2008 from: http://ferris.edu/fctl/Teaching_and_Learning_Tips/.../EvalTeachEffec.htm

EURYDICE. 2008. Úrovne autonómie a zodpovednosti učitel'ov v Európe. Brussels, 2008. Available at: http://eacea.ec.europa.eu/education/eurydice/documents/thematic_reports/094S K.pdf

FRANC, D. - ZOUNKOVÁ, D.: Učení zážitkem a hrou. Brno: Computer Press, 2007. HOYT, D. P. - PALLETT, W. H.: Appraising teaching effectiveness: Beyond student ratings. Idea Center. Idea Paper No. 36. Kansas State University, 1999. Available at: http://www.theideacenter.org/sites/default/files/Idea_Paper_36.pdf 